\title{
Discussion on the Development Barriers of BIM Construction Costs in China
}

\author{
Qirui Zhang ${ }^{1, *}$, Bin Guo ${ }^{2}$ \\ ${ }^{1}$ Polytechnic Institute of Engineering Management, Zhejiang University, Hangzhou, China \\ ${ }^{2}$ Library, Zhejiang University of Science and Technology, Hangzhou, China \\ Email address: \\ 463730061@qq.com (Qirui Zhang), 124702308@qq.com (Bin Guo) \\ ${ }^{*}$ Corresponding author
}

\section{To cite this article:}

Qirui Zhang, Bin Guo. Discussion on the Development Barriers of BIM Construction Costs in China. American Journal of Civil Engineering. Vol. 7, No. 5, 2019, pp. 133-140. doi: 10.11648/j.ajce.20190705.13

Received: November 4, 2019; Accepted: November 25, 2019; Published: December 3, 2019

\begin{abstract}
BIM is regarded as a new problem-solving method in the field of architecture construction. With the continuous development and progress of BIM, it also has a series of impacts on the field of project cost. In this paper, through literature research, expert interviews, questionnaires, data analysis, and other ways, the current front-line AEC (architecture, Engineering \& Construction) practitioners were investigated. This paper investigates the understanding of BIM in the field of construction cost and the current development obstacles and makes a cross-analysis of the development obstacles of various industries. It is found that technology is the most important obstacle in technology, economy, society and other factors, and how to solve the problem of model standardization and accuracy is the most important part. In the cross research of technical problems and professions, we found that there are many deficiencies in the modeling function of current BIM software, and there are also some problems in the transformation of two-dimensional and three-dimensional data, which are considered as obstacles of the whole industry. The research results of this paper can be used as a practical reference for future research, trying to provide technical and management solutions for the implementation and development of BIM in the construction cost of our country.
\end{abstract}

Keywords: BIM, Construction Cost, Develop Barriers

\section{Introduction}

The productivity of the construction industry has lagged that of many other industries, which equally threatening and chances. [1] The modern information technologies will help to change this situation. Particularly, building information modeling (BIM) is with evident benefits facilitating the project management in terms of better coordination and information management for decision making. Construction costs are a very important segment in the life cycle management of buildings. There are also some challenges in the development of BIM. In order to better carry out the whole life cycle management of buildings, we need to understand the current obstacles in BIM development in this field.

\section{1. $B I M$}

Building information modeling (BIM) is a process supported by various tools and technologies involving the generation and management of digital representations of physical and functional characteristics of places. BIMs are files (often but not always in proprietary formats and containing proprietary data) that can be extracted, exchanged or networked to support decision-making regarding a built asset. [2] Current BIM software is used by individuals, business and government agencies who plan, design, construct, operate and maintain diverse physical infrastructure, such as water, electricity, gas, transportation (roads, railways, bridges, ports, tunnels).

The concept of BIM was initiated by Charles M. Eastman in the 1970s and started growing from the 1980s in the European countries [3]. Moreover, in recent years, its implementation and adoption have become widespread in some developed countries such as the United States, the United Kingdom, Norway, Finland, Sweden, Denmark, Singapore and Hong Kong [4]. Bernstein et al. [5] reported that rapid growth in its global appeal and that a broader set of construction companies have committed resources towards the adoption and 
implementation of BIM for their construction projects.

CIC further expressed BIM as a "new way of working, using new technology to facilitate project management and execution, better construction process control, cross-disciplinary collaboration, internal coordination, external communication, problem-solving, and risk management." From the above definitions, it can be concluded that Building Information Modeling is not just a designing tool but a system to manage the project during its life cycle. [6]

Therefore, BIM is an important development engine in the field of AEC in the future. Understanding the current development obstacles of BIM is an important link to help the development of BIM.

\subsection{Construction Costs}

\subsubsection{Construction Costs in Different Countries}

Because of the different cultures of different countries, the calculation rules of quantities are different in different countries. As early as the 17 th century, the concept of "engineering surveyor" appeared in the engineering management of England. The traditional valuation model of construction projects in the UK is compiled and summarized according to the standard method of measurement of building works SMM, which is organized and formulated by the Royal Society of Surveyors. The government does not intervene and indirectly manage, so the UK attaches great importance to the legal system to restrict market prices. [7]

The birth of the pricing model of cost engineering management in North America is mainly due to the fact that the American government does not organize the formulation of a pricing basis, nor does it have the national unified pricing basis and standard. The norms, indicators and cost standards related to project cost are unified, but they are generally formulated by large-scale engineering consulting companies. The standards developed by the federal government, state government and local government of the United States refer to the engineering consulting unit as the basis for estimating the project cost in the jurisdiction. [8]

Japan is a market economy model dominated by the government. The competent government departments and the building accumulation Association uniformly manage and guide the project cost. The characteristics of Japan are strict budget control, different management of government projects and private investment projects. Public buildings shall be managed by the competent construction Department of the government in the whole process of construction quota and pricing basis. [9]

Due to the different calculation rules and norms between different countries, the software should not be used in the construction costs.

At present, automating processes in construction costs like material take-off and cost estimation with BIM can allow contractors to spend less time on material take-offs and more time reviewing and planning the project. Automated measurement is one method to speed up the material take-off processes. [10]
Table 1. Comparison of engineering calculation rules in different countries.

\begin{tabular}{llll}
\hline & UK & USA & Japan \\
\hline Unified calculation rules and quotas & yes & no & yes \\
Project centralized management department & yes & no & yes \\
\hline
\end{tabular}

\subsubsection{Development Status of Construction Costs in BIM}

With the rapid development of the construction industry recently, although the large-scale construction enterprises' advantages gradually emerged, it is common of low management efficiency, low profitability, backward construction management, and risk response-ability and other reasons. Construction enterprises win the project through competition and lower prices, leading to the enterprise's internal core competitiveness has not been taken seriously, which resulted in the weakness of construction enterprise management capacity. However, China has become one of the world's largest construction markets, with the rapid development of the construction industry, it is expected that China's urbanization rate will reach $55 \%$ by 2020 and increase to more than $76 \%$ by 2052 .

However, the construction industry's low efficiency and the high waste phenomenon are hindering the construction industry, the bottleneck of rapid development, the construction process more and more tedious. And construction-related information is redundant and real-time variable, the main construction and construction processes between the effective exchange of information and collaboration are difficult. Therefore, the construction of the actual demand from the realization of building information and intelligent is the development of the construction industry hot and trend.

With the increasing application of BIM technology in construction projects, BIM technology in the construction phase of the application more and more mature, but the current BIM technology in the construction phase of the application there are professional deepening design model integration difficulties, the lack of standard reference, It is difficult to deepen the design model to improve the project, the lack of BIM-based construction management system, BIM lack of talent and many other issues. Therefore, it is the direction of research and application of BIM technology in construction industry to realize the sharing of construction models through the integration of BIM 5D platform for all information of construction project, unified modeling norms and modeling standards. [11]

In this environment, BIM 5D was born.5D BIM, an acronym for 5-dimensional building information modeling, is a term used in the CAD and construction industries and refers to the intelligent linking of individual $3 \mathrm{D}$ CAD components or assemblies with time schedule (4D BIM) constraints [12]

$$
5 \mathrm{D}=3 \mathrm{D}+\mathrm{TIME} \text { SCHEDULE }+ \text { COST }
$$

The creation of 5D models enables the various participants (from architects, designers, contractors to owners) of a construction project to visualize the progress of construction activities and its related costs over time. [13, 14] This BIM-centric project management technique has the potential 
to improve management and delivery of projects of any size or complexity. [15]

$5 \mathrm{D}$ integrates all of this information with cost data such as quantities, schedules and prices.

Dr. Peter Smith concludes with the findings that the greatest value with the modern-day project cost manager lies in their ability to be 5D literate and to be able to utilize electronic models to provide detailed 5D estimates and living cost plans in real-time. [16]

Therefore, we need to study the development of construction costs in BIM.

\subsection{Current Problems}

Through the literature investigation, we found that these phenomena. In the field of engineering cost, the accuracy of the model can increase users' confidence in BIM. [17]

In Sweden, the question arose as to whether the lack of internal or external demand was the main reason for non-users to use BIM. Although the respondents appeared to agree that BIM was generally user-friendly and that the complexity of the model was not a major obstacle, there were significant differences between users and non-users in this aspect. Users to a much higher degree than the non-users of BIM believed that BIM-use required high investments in hardware and software. [18]

In Saudi Arabia, technology such as Building Information Modeling (BIM) could help transform the construction industry in Saudi Arabia and improve the final outcomes. Abdulaziz Banawi's through a questionnaire to identify the barriers of implementing BIM technology. Additional barriers are also identified through a case study for a public project after implementing BIM trough the feasibility and the design phase. The barriers are fallen under tow categories including; process implementing which comes first and technology and resources that come second [19].

Ke Chen found that previous literature is in-depth but is distant from the market, which has failed in analyzing the basic reasons lying behind. BIM has been introduced to Architecture, Engineering, and Construction (AEC) participants for more than two decades, but its adoption rate is still lethargic. The current construction industry remains disciplines-fragmented and interoperability-inadequate. These obstinate defects, together with the increasing attention of both academics and industry professionals on how to successfully improve BIM, suggest the market's reluctance to adopt BIM and highlight the inquiry into reasons lie behind. He thought the main barriers focus on economic factors. Since BIM adoption involves opportunity costs, stakeholders would choose to adopt BIM at the market-determined time. And due to the social costs/benefits of using BIM, the market-determined timing of BIM adoption tends to be delayed, the governments' enforcing BIM hence is reasonable. And the compulsory requirements on clarifications of the responsibilities and the corresponding benefits among AEC discipline reinforces the importance of governments in promoting BIM implementation. [20]

Through professional interviews and research find that the main application software of BIM in the field of construction costs mainly has the following problems:

There is much software in foreign countries, but the measurement standards at home and abroad are different, which need to be modified manually; pricing lacks modules. So it is impossible to carry out automatic calculation; there are difficulties in information transmission. It is impossible to achieve full-cycle management, etc. In order to realize the automation of cost, we must solve the problem of realizing the automatic measurement of engineering quantity and applying the cost specification. The development of BIM is a good opportunity for the development of construction costs. We conduct research on professionals in various industries, analyze obstacles and explore solutions.

\subsection{Conclusion}

This paper is structured as follows. Section 1 introduces the background of the study and the concept of BIM. Section 2 reviews the literature on development barriers of BIM in both China and other countries. Section 3 discusses the adopted research designs and the statistical tools employed in the study. Section 4 highlights the study's significant findings. Section 5 encapsulates the practical implications of the study and assess the perceived benefits of and potential barriers to BIM implementation in future building environment.

\section{Method}

This study follows a three-step research design to achieve the objectives of this research (see Figure 1). First, a preliminary identification of barriers that could affect BIM implementation in China's construction cost. Next, a questionnaire survey with practitioners was carried out in order to filter the barriers that specifically affect BIM in construction costs in China. The final step was to analyze the data and give some advice to future development.

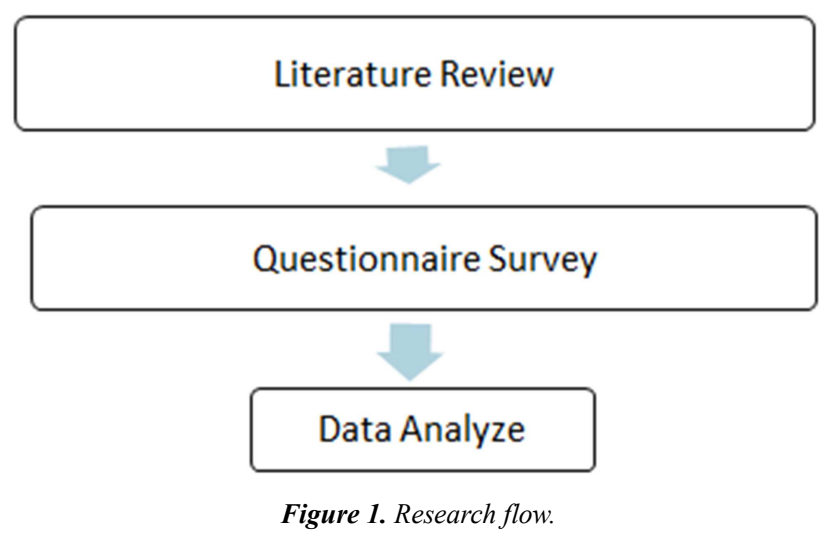

The main method is to carry out an expert investigation and questionnaire survey on the factors that hinder the development of BIM in the application of project cost. Find out the main reasons that hinder the development of BIM. As well as the analysis of the impact of the development of BIM on various engineering professional fields in the project cost. 


\subsection{Literature Research}

First of all, literature research is a very important and effective method in the research process. Through the study of the relevant literature in recent years, we can quickly grasp the development and the latest research in this field.

The search rule in this study was ("BIM" OR "building information modeling" OR "building information modeling" OR "building information model" OR "construction costs" OR "cost" OR "barrier" OR "develop barriers". To avoid omissions of target papers, the time-span of the publication search was set for "all years". According to the first criterion, a total of 88 journal papers were retrieved.

Tan Tan conducted a two-round literature review and a questionnaire survey ascertained twelve barriers acutely affecting the Chinese experience of applying BIM to prefabricated construction. In his survey, the influencing factors are divided into five categories, including technology, management, environmental, financial and legal. The exercise found that, compared with the cost-related issues suggested by previous studies that focused on general BIM implementation barriers, the lack of research about BIM in China and the absence of standards and domestic-oriented tools are likely the biggest hindrances to the practical application of BIM in China's prefabricated construction. This study contributes to the knowledge body by revealing major barriers to BIM implementation in China's prefabricated construction and crafting a corresponding three-level strategy to facilitate the possible implementation. The findings of this study can thus act as a practical reference for future research attempting to provide technological and managerial solutions to improve BIM implementation in China's prefabricated construction. [21]

For the factors influencing the economic performance of construction, Jingke Hong divided into higher costs and lower costs. The higher costs include 9 factors, including highly skilled workers, complex techniques, complex design and so on. And the lower costs include 11 factors, like Increased productivity, decreased management cost, controlled quality and so on. This survey is conducted through the combined methods of site investigation, questionnaire, and face-to-face interviews with designers, project managers and prefabrication suppliers associated with the target projects. One important part represents the prefabrication information including the volume of prefabrication, prefabrication rate, and volume of each type of prefabricated component used in the target project, which aims to explore the features of the sample prefabricated buildings and establish the quantitative basis for cost estimation. One important conclusion is that the level of maturity in the local construction market directly determines the cost-effectiveness of precast construction. [22]

By examining 73 journal articles on collaboration in BIM-based construction networks, Mehran Oraee built upon a theoretical review of the literature. In his research, he focuses on collaboration barriers. He divided the process-related barriers to collaboration influence factors into
3 categories, including tools, resources, and training. And he divided the context-related barriers to collaboration to collaboration influence factors into 3 categories, including environment, organization, culture. And he thought the actor-related barriers to collaboration is the skill. Besides, the other barriers include composition, relationships, roles, structure, and demand. This study contributes to the field of collaboration and its impact on project management in several ways. [23]

Daniel W. M. Chan found that the five most profound barriers are cultural barriers (resistance to change), the organizational structure that does not support BIM, insufficient interoperability of computer software, lack of industry standards, and difficulties in measuring impacts of BIM. Moreover, the five most important benefits include better cost estimates and control, a better understanding of design, reduce construction cost, better construction planning and monitoring, and improvement of project quality. The BIM consultants and contractors underscore the importance of BIM to speed up the design process. Also, there was a relatively good level of consensus among the respondents' groups on the identified barriers and benefits. More so, some research studies corroborated the findings of this study as prevalent in other climes. [24]

Xiaolong Gan's paper pointed out that rapid urbanization and the emergence of information technology for the construction industry provide the best opportunity for adopting OSC. There are a number of benefits associated with OSC adoption such as cost savings, time savings, less waste, and improved efficiency. However, The OSC adoption still remains its infancy in China. This research identified 13 critical barriers to the OSC adoption. By conducting ISM analysis, these 13 barriers are structured in a hierarchy and divided into five distinct levels. Then, by applying the MICMAC analysis, one autonomous factor, six independent factors, and seven dependent factors were identified. It is more effective to address the independent factors as they are most influential to impede the OSC adoption. Similarly, the advantages of OSC can be used to reduce the intensity of barriers. [25]

By Thuy Duong Oesterreich's research found that it can be concluded that the barriers to BIM adoption are primarily rooted in the social behavior of the actors as well as the social arrangements of the construction industry rather than technical issues in general. In order for the industry-wide adoption of BIM to be successful, concerted efforts are required from various individuals and industry groups, such as construction companies, designers, project owners, BIM vendors and governmental bodies to overcome the human and structural barriers. Against this background, the research provides researchers and industry practitioners with a set of propositions that can be taken into account when making decisions towards BIM adoption. These propositions should serve as an aid for gaining an enhanced understanding of the adoption barriers prior to developing coping strategies. [26] 


\subsection{Questionnaire Survey Design}

The survey interviewed the owner company, design enterprise, construction enterprise, a consulting company, and government agencies, collected 192 effective samples, and selected $41 \mathrm{key}$ obstacles. According to the correlation analysis between the occupation field and the key obstacles, the conclusion is drawn.

The design of the questionnaire includes the working time of the respondents, whether the respondents know the BIM model and the 10 key obstacles to the development of BIM. The obstacles for selection are shown in the table below.

Table 2. Development barriers.

Low localization of foreign BIM Products

Lack of domestic BIM Technology Products

Lack of standardized BIM object library

Insufficient data source for BIM model input

Lack of research on BIM Technology in China

Incomplete of modeling function of BIM design software

For BIM software errors, lack of technical countermeasures

Incompatible with traditional 2D and 3D data, the workload of designers

increases

The accuracy detection method of BIM model is not perfect

The scalability of BIM function is not strong

Lack of professional interaction

Lack of open electronic information exchange platform based on BIM

Misunderstanding of BIM Technology

Adapt to the change of thinking mode

Resistance to new technology

Negative attitude towards sharing data resources

Cost and time of training employees

Cost of BIM software purchase

Cost of hardware upgrade

Cost of hiring BIM experts and consultants

Increase of design cost

The economic benefits of BIM Technology are not obvious

Insufficient external motivation

Lack of learning resources of BIM Technology

Lack of skilled operators and experts in BIM software

Lack of practical experience and academic exchange of BIM project

No BIM standards and guidelines issued by policy departments and industry authorities

Lack of systematic BIM training courses

BIM based workflow has not been established

Project participants are not accustomed to collaborative work mode

Not every participant will use BIM software

Increased workload of designers

The version and security management of BIM model is very difficult

Risk of business process reengineering based on BIM

Not accustomed to BIM's collaborative work mode

Lack of clear objectives for BIM adoption within the organization

No long-term BIM application plan within the organization

Lake of BIM standard contract model text

Lack of insurance provisions for BIM

Lack of legal provisions and measures to protect the intellectual property rights of BIM model

The dispute settlement mechanism in BIM project is not mature

\section{Analysis}

\subsection{Descriptive Analysis}

Among the 192 questionnaires collected, 29.46\% were from the design industry, $20.16 \%$ from the cost industry,
$32.56 \%$ from the construction industry and $17.82 \%$ from other related industries.

Table 3. Industry Distribution.

\begin{tabular}{ll}
\hline Profession & Proportion \\
\hline Architectural design & $29.46 \%$ \\
Engineering cost & $20.16 \%$ \\
Building construction & $32.56 \%$ \\
Others & $17.82 \%$ \\
\hline
\end{tabular}

Among the 129 people interviewed, 31 were employed for less than 5 years (including 5 years), accounting for $24.03 \%$; 39 for 5-.10 years (including 10 years), accounting for $30.23 \%$; 56 for $10-20$ years (including 20 years), accounting for $43.41 \%$; 3 for more than 20 years, accounting for $2.33 \%$. Among them, 105 people knew BIM, accounting for $81.4 \%$; 24 people did not know BIM, accounting for $18.6 \%$.

Table 4. Proportion of cognitive BIM.

\begin{tabular}{lll}
\hline & Number of people & Proportion \\
\hline Know & 105 & $81.40 \%$ \\
Don't know & 24 & $18.60 \%$ \\
\hline
\end{tabular}

\section{Distribution of employment time}

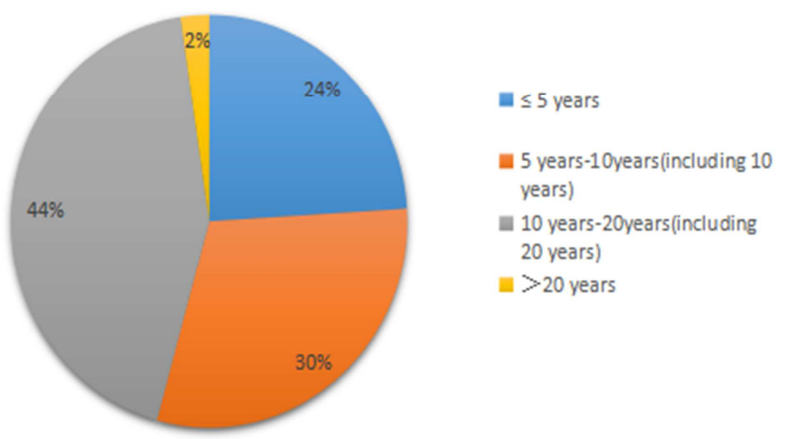

Figure 2. Distribution of employment time.

Table 5. Distribution of employment time.

\begin{tabular}{lll}
\hline Employment time & Number of people & Proportion \\
\hline $\begin{array}{l}\leq 5 \text { years } \\
\text { 5 years-10years (including 10 }\end{array}$ & 31 & $24.03 \%$ \\
$\begin{array}{l}\text { years) } \\
10 \text { years-20years (including } 20\end{array}$ & 39 & $30.23 \%$ \\
$\begin{array}{l}\text { years) } \\
>20 \text { years }\end{array}$ & 56 & $43.41 \%$ \\
\hline
\end{tabular}

Among the 105 people who know BIM, the top 10 reasons are:

Table 6. Top 10. development barriers.

\begin{tabular}{lll}
\hline & Number & Proportion \\
\hline $\begin{array}{l}\text { 3. Lack of standardized BIM object library } \\
\text { 2. Lack of domestic BIM Technology Products }\end{array}$ & 41 & $36.05 \%$ \\
$\begin{array}{l}\text { 4. Insufficient data source for BIM model } \\
\text { input }\end{array}$ & 34 & $34.29 \%$ \\
$\begin{array}{l}\text { 6. Incomplete of modeling function of BIM } \\
\text { design software }\end{array}$ & 32 & $32.38 \%$ \\
$\begin{array}{l}\text { 8. Incompatible with traditional 2D and 3D } \\
\text { data, the workload of designers increases }\end{array}$ & 32 & $30.48 \%$ \\
\begin{tabular}{l} 
17. Cost and time of training employees \\
\hline
\end{tabular} & 30 & $28.57 \%$ \\
\hline
\end{tabular}




\begin{tabular}{lll}
\hline & Number & Proportion \\
\hline 5. Lack of research on BIM Technology in & 28 & $26.67 \%$ \\
China & 28 & $26.67 \%$ \\
18. Cost of BIM software purchase & 27 & $25.71 \%$ \\
11. Lack of professional interaction & 26 & $24.76 \%$ \\
31 Not every participant will use BIM & & \\
software &
\end{tabular}

From a single dimension, it can be seen that when choosing the reasons for obstruction, people tend to prefer technical problems as the main reason for hindering the development of BIM cost. Among the technical problems, it mainly focuses on the standardization and accuracy of the model. To further verify, we do some correlation analysis on the questionnaire.

\subsection{Correlation Analysis}

\subsubsection{Analysis of Cause Angle}

To better improve the application environment of BIM, we need to understand the obstacles more comprehensively and objectively. We think that the obstacles are mainly four dimensions: economic obstacles, technological obstacles, social obstacles, and other obstacles (mainly including internal reasons of the company, personal internal reasons, etc.). The reasons in the questionnaire are classified into four dimensions. Calculate the total number of votes for each dimension, divided by the number of reasons for the classification. Compare the average of each dimension:
Table 7. Classification of four dimensions.

\begin{tabular}{ll}
\hline Cause & Number \\
\hline Technology & 1.2 .3 .4 .5 .6 .7 .8 .9 .10 .11 .12 \\
Economic & 17.18 .19 .20 .21 .22 \\
Society & 13.14 .15 .16 .27 .38 .39 .40 .41 \\
Others & 23.24 .25 .26 .27 .28 .29 .30 .31 .32 .33 .34 .35 .36 .37 \\
\hline
\end{tabular}

Table 8. Sum of four dimensions.

\begin{tabular}{lllll}
\hline Cause & $\begin{array}{l}\text { Cause } \\
\text { number }\end{array}$ & $\begin{array}{l}\text { Sum of } \\
\text { dimensions }\end{array}$ & $\begin{array}{l}\text { Average number } \\
\text { of dimensions }\end{array}$ & Proportion \\
\hline Technology & 12 & 320 & 26.66 & $45.91 \%$ \\
Economic & 6 & 115 & 19.166 & $16.50 \%$ \\
Society & 9 & 91 & 10.111 & $13.06 \%$ \\
Others & 15 & 171 & 11.4 & $24.53 \%$ \\
\hline
\end{tabular}

The most important 10 items are selected in the questionnaire, so there is no difference in weight. According to the voting analysis of the four influencing factors, we believe that the most important obstacles to development are mainly in the field of technology and economy, in which the proportion of BIM cost development affected by technology is much higher than other factors. Therefore, we need to vigorously solve the technical problems in this field.

\subsubsection{Analysis Between Cause and Profession}

In addition to the dimension of influence, we also consider whether it is career-related. So, let's say, is there a correlation between the cause of obstruction and occupation? In terms of the above, we have made a correlation analysis.

For the technical dimension, the analysis is as follows:

Table 9. Analysis between technology cause and profession.

\begin{tabular}{llc}
\hline Technology cause & Architectural design & Engineering cost Building construction \\
\hline 1. Low localization of foreign BIM Products & -0.079 & 0.132 \\
2. Lack of domestic BIM Technology Products & -0.062 & $0.311^{* *}$ \\
3. Lack of standardized BIM object library & -0.027 & $0.282^{* *}$ \\
4. Insufficient data source for BIM model input & -0.012 & 0.161 \\
5. Lack of research on BIM Technology in China & -0.082 & 0.2 \\
6. Incomplete of modeling function of BIM design software & -0.08 & 0.071 \\
7. For BIM software errors, lack of technical countermeasures & -0.079 & 0.154 \\
8. Incompatible with traditional 2D and 3D data, the workload of designers increases & -0.08 & 0.189 \\
9. The accuracy detection method of BIM model is not perfect & -0.046 & 0.154 \\
10. The scalability of BIM function is not strong & -0.079 & 0.159 \\
11. Lack of professional interaction & 0.005 & $0.243 *$ \\
12. Lack of open electronic information exchange platform based on BIM & -0.049 & 0.243 \\
\hline
\end{tabular}

$* \mathrm{p}<0.05 * * \mathrm{p}<0.01$

Data shows that there is no direct relationship between the three professions of architectural design, engineering cost and building construction and technical reasons.

Table 10. Analysis between economiccause and profession.

\begin{tabular}{|c|c|c|c|}
\hline & Architectural design & Engineering cost & Building construction \\
\hline 1. Cost and time of training employees & 0.015 & 0.032 & $0.318 * *$ \\
\hline 2. Cost of BIM software purchase & -0.08 & 0.1 & $0.279 * *$ \\
\hline 3. Cost of hardware upgrade & -0.078 & 0.108 & 0.269 \\
\hline 4. Cost of hiring BIM experts and consultants & -0.046 & 0.099 & $0.290 * *$ \\
\hline 5. Increase of design cost & -0.015 & 0.091 & 0.232 \\
\hline 6. The economic benefits of BIM Technology are not obvious & -0.078 & 0.168 & $0.310 * *$ \\
\hline
\end{tabular}

$* \mathrm{p}<0.05 * * \mathrm{p}<0.01$

Data shows that there is no direct relationship between the three professions of architectural design, engineering cost 
and building construction and technical reasons.

\subsubsection{Analysis of Technical Barriers}

Through the previous analysis, we can find that. Technical hindrance is the biggest hindrance in the development of BIM costs. Then, in the technical barriers, we will analyze two kinds of reasons. One is the one with the largest number of votes, and the other with the smallest variance (indicating that all occupations approve it most consistently).

Table 11. Top five technological barriers.

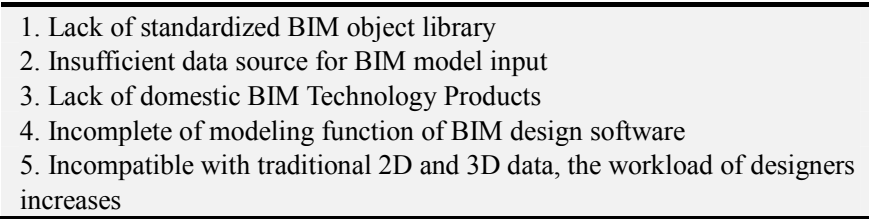

The standard deviation is the square root of the arithmetic mean of the square of the mean deviation. In probability statistics, it is most commonly used as a measure of the degree of statistical distribution. The small standard deviation indicates that the three industries have the most consistent recognition of this reason; the large standard deviation indicates that the recognition of the importance of this reason in different industries is not so consistent.

To find out whether the three professions agree on the reasons, we first deal with the number of votes (reason votes / total number of professions) to exclude the impact of the difference in the number of professions. Then, a standard deviation is calculated by the processed value, and the results are compared.

We choose the five reasons with the lowest standard deviation, which means that these five reasons are the barriers that the three professions think they faced together.

Table 12. Standard deviation of technology barriers.

\begin{tabular}{|c|c|}
\hline technology barriers & $\begin{array}{l}\text { standard } \\
\text { deviation }\end{array}$ \\
\hline 1. Incomplete of modeling function of BIM design software & 0.0165047 \\
\hline 2. The scalability of BIM function is not strong & 0.0182525 \\
\hline $\begin{array}{l}\text { 3. Incompatible with traditional } 2 \mathrm{D} \text { and } 3 \mathrm{D} \text { data, the } \\
\text { workload of designers increases }\end{array}$ & 0.0183485 \\
\hline 4. Lack of professional interaction & 0.0222678 \\
\hline $\begin{array}{l}\text { 5. The accuracy detection method of BIM model is not } \\
\text { perfect }\end{array}$ & 0.0237578 \\
\hline 6. Lack of domestic BIM Technology Products & 0.0293702 \\
\hline $\begin{array}{l}\text { 7. For BIM software errors, lack of technical } \\
\text { countermeasures }\end{array}$ & 0.0319865 \\
\hline 8. Insufficient data source for BIM model input & 0.0427116 \\
\hline 9. Lack of standardized BIM object library & 0.0427460 \\
\hline $\begin{array}{l}\text { 10. Lack of open electronic information exchange platform } \\
\text { based on BIM }\end{array}$ & 0.0452259 \\
\hline 11. Lack of research on BIM Technology in China & 0.0690582 \\
\hline 12. Low localization of foreign BIM Products & 0.0822781 \\
\hline
\end{tabular}

Through comparison, we find that Incomplete of modeling function of BIM design software and incompatible with traditional $2 \mathrm{D}$ and $3 \mathrm{D}$ data and The workload of designers increases, not only has a large number of votes but also has a high degree of professional consensus.

\section{Conclusion}

Through literature research, expert interviews, questionnaire survey, and data analysis, this study takes front-line designers, project cost engineers and builders as the research objects to understand the main obstacles and important obstacles of BIM development in the field of the project cost. Through the discovery of obstacles, we hope that future research can solve the existing obstacles more specifically.

It can be concluded that BIM has some barriers in the field of project cost, but more opportunities.

First of all, due to the cultural differences of each country, the differences in the calculation methods of quantities, and the differences in policies and regulations, the development of BIM in the aspect of project cost needs to be localized.

Secondly, through the investigation, it is found that among the four main factors of technical, economic, social and other reasons, technical reasons are recognized as the main obstacles to the cost development of BIM projects.

Third, among the technical reasons, we try to find the consensus reasons among industries, to solve the common problems of the whole industry at the lowest cost. Considering the influence of the number of people in each industry on the data, we remove the industry interference factors and find that the most important obstacle to be solved is the modeling function of BIM software and the conversion of $2 \mathrm{D}$ and $3 \mathrm{D}$ data.

In the future, we hope that the government, market, and researchers can focus on the technology and pay more attention to the modeling function of BIM software and the conversion of $2 \mathrm{D}$ and $3 \mathrm{D}$ data. Thus, promote the development of construction costs in BIM field.

\section{References}

[1] Koskela L (1992) Application of the new production philosophy to construction (No. 72). Stanford University, Stanford, CA.

[2] http://wikipedia.moesalih.com/BIM\#Japan

[3] A. K. D. Wong, F. K. W. Wong, A. Nadeem, Government roles in implementing building information modelling systems: comparison between Hong Kong and the United States, Construction Innovation: information, Process, Management 11 (2011) 61-76, https://doi.org/10.1108/14714171111104637.

[4] L. Khemlani, Around the World with BIM, (2012) http://www.aecbytes.com/feature/2012/Global-BIM.html.

[5] H. M. Bernstein, S. Jones, M. Russo, The Business Value of BIM in North America: Multi-Year Trend Analysis and User Rating (2007-2012), (2012).

[6] "The Hong Kong Construction Industry Council" CIC, Final Draft Report of the Roadmap for BIM Strategic Implementation in Hong Kong's Construction Industry, (2013).

[7] Wang Zhenqiang, UK engineering cost management. Nankai University Press. 2002. 
[8] Hao Jianxin, Cai Shaorong, American engineering cost management, Nankai University Press, 2002.

[9] Wang Zhenqiang, Xia Liming. Japanese engineering cost management. Nankai University Press. 2002).

[10] Tulke, J., Nour, M., Beucke, K.: A dynamic framework for construction scheduling based on BIM using IFC. IABSE Congress Report. https://doi.org/10.2749/222137908796292119.

[11] Jiang Xu, Research on Application of BIM 5D Technology in Central Grand Project, 13th Global Congress on Manufacturing and Management, GCMM 2016, Procedia Engineering 174 (2017) $600-610$, http://creativecommons.org/licenses/by-nc-nd/4.0/)]

[12] "Introduction to 4D Research by Martin Fischer". stanford.edu. Retrieved 29 May 2012.] and then with cost-related information. ["ASHRAE Introduction to BIM, 4D and 5D". cadsoft-consult.com. Archived from the original on 3 April 2013. Retrieved 29 May 2012.

[13] "NIBS BIM Initiatives". wbdg.org. Retrieved 29 May 2012.

[14] "5D BIM from Vico website". vicosoftware.com. Retrieved 29 May 2012.

[15] Mills, Fred. "What is 5D BIM?". www.TheB1M.com. The B1M Limited. Retrieved 8 April 2016.

[16] Dr. Peter Smitha, BIM \& the 5D Project Cost Manager, 27th IPMA World Congress, Procedia - Social and Behavioral Sciences $119 \quad$ (2014) $475 \quad-\quad 484, \quad$ doi: 10.1016/j.sbspro.2014.03.053.

[17] I. Mutis and T. Hartmann (eds.), Barriers of Automated BIM Use: Examining Factors of Project Delivery, Advances in Informatics and Computing in Civil and Construction Engineering, 2019, p3-9.

[18] Petra Bosch-Sijtsema, Anders Isaksson, Martin Lennartsson and Henrik C. J. Linderoth, Barriers and facilitators for BIM use among Swedish medium-sized contractors - "Wewait until someone tells us to use it", Bosch-Sijtsema et al. Visualization in Engineering (2017) 5:3.

[19] Abdulaziz Banawi, Barriers to Implement Building
Information Modeling (BIM) in Public Projects in Saudi Arabia, Advances in Human Factors, Sustainable Urban Planning and Infrastructure, Advances in Intelligent Systems and Computing 600, DOI 10.1007/978-3-319-60450-3_12, 2018, p119-125.

[20] Ke Chen, Weisheng Lu, Yi Peng ect, An Investigation of the Latent Barriers to BIM Adoption and Development, Proceedings of the 20th International Symposium on Advancement of Construction Management and Real Estate, DOI 10.1007/978-981-10-0855-9_89, 2017, p1007-p1017.

[21] Tan Tan, Ke Chen, Fan Xue, Weisheng Lu, Barriers to Building Information Modeling (BIM) implementation in China's prefabricated construction: An interpretive structural modeling (ISM) approach, Journal of Cleaner Production 219 (2019) 949e959.

[22] Jingke Hong, Geoffrey Qiping Shen, Zhengdao Li, Boyu Zhang, Wanqiu Zhang, Barriers to Promoting Prefabricated Construction in China: A Cost-Benefit Analysis, Journal of Cleaner Production (2017), doi: 10.1016/j.jclepro.2017.10.171 p1-p25.

[23] Mehran Oraee, M. Reza Hosseini, David J. Edwards, Heng Li, Eleni Papadonikolaki, Dongping Cao, Collaboration barriers in BIM-based construction networks: A conceptual model, International Journal of Project Management 37 (2019) 839854., https://doi.org/10.1016/j.ijproman.2019.05.004

[24] Daniel W. M. Chan, Timothy O. Olawumi*, Alfred M. L. Ho, Perceived benefits of and barriers to Building Information Modelling (BIM) T implementation in construction: The case of Hong Kong, Journal of Building Engineering 25 (2019) 100764, https://doi.org/10.1016/j.jobe.2019.100764.

[25] Xiaolong Gan, Ruidong Chang, Jian Zuo, Tao Wen, George Zillante, Barriers to the transition towards off-site construction in China: An Interpretive structural modeling approach, Journal of Cleaner Production 197 (2018) 8e18, https://doi.org/10.1016/j.jclepro.2018.06.184.

[26] Thuy Duong Oesterreich, Frank Teuteberg, Behind the scenes: Understanding the socio-technical barriers to BIM adoption through the theoretical lens of information systems research, Technological Forecasting \& Social Change 146 (2019) 413431, https://doi.org/10.1016/j.techfore.2019.01.003. 